\title{
Effect of angiogenesis inhibitors on oestrogen-mediated endometrial endothelial cell proliferation in the ovariectomized mouse
}

\author{
B. Heryanto ${ }^{1}$, K. E. Lipson ${ }^{2}$ and P. A. W. Rogers ${ }^{1 *}$ \\ ${ }^{1}$ Centre for Women's Health Research, Monash University Department of Obstetrics and Gynaecology, \\ Monash Medical Centre, 246 Clayton Road, Clayton, Victoria 3168, Australia; and ${ }^{2}$ SUGEN Inc. \\ 230 East Grand Avenue, South San Francisco, CA 94080, USA
}

\begin{abstract}
It has been suggested that endometrial angiogenesis in response to the sex steroids oestrogen and progesterone is mediated at a local level via compounds such as vascular endothelial growth factor (VEGF), fibroblast growth factor (FGF) and platelet-derived growth factor (PDGF), acting through their respective tyrosine kinase receptors. The aim of the present study was to use SUGEN tyrosine kinase receptor angiogenic inhibitor compounds SU5416, SU5402, SU11652 and SU11685, to determine whether VEGF, FGF or PDGF play a role in mediating endometrial endothelial cell proliferation after administration of oestrogen and progesterone. Endometrial endothelial cell proliferation was induced in adult ovariectomized mice by either oestrogen alone for $24 \mathrm{~h}$ (E1), or a regimen using oestrogen alone, then progesterone with low dose oestrogen, followed by progesterone with high-dose oestrogen (PE) over a total of 7 days. Each angiogenesis inhibitor compound was injected daily for 4 days (100 $\mathrm{mg} \mathrm{kg}^{-1} \mathrm{day}^{-1}$, s.c.) before
\end{abstract}

endometrial tissue collection at either the E1 or PE stage. This study also evaluated the effect of VEGF antiserum $(0.2 \mathrm{ml}$, i.p.) on endothelial cell proliferation at the E1 stage. All four angiogenic inhibitor compounds significantly reduced endothelial cell proliferation activity at the $\mathrm{E} 1$ and PE stages. The greatest reduction in the endothelial cell proliferative index was at the E1 stage in the group treated with the VEGF receptor inhibitor SU5416 $(2.5 \pm 0.7 \%$ versus $27.9 \pm 1.1 \%, P<0.001)$, with a reduction of similar magnitude in the group treated with anti-VEGF antibody. At the PE stage, all four inhibitors significantly reduced endothelial cell proliferation to a similar extent, indicating that VEGF, FGF and PDGF are all involved. These results demonstrate that endometrial angiogenesis after acute oestrogen treatment is primarily mediated by VEGF, but that under the influence of combined oestrogen and progesterone, FGF and PDGF are also probably involved.

\section{Introduction}

Angiogenesis occurs regularly in association with cyclical changes in the adult female endometrium (Rogers and Gargett, 1999; Weston and Rogers, 2000). Investigation of hormonal regulation of endometrial angiogenesis in the ovariectomized mouse has shown that endothelial cell proliferation occurs under at least two different hormonal regimens: an early, rapid response to oestrogen alone, and a longer-term response to sequential progesterone and low-dose oestrogen followed by progesterone and high-dose oestrogen (Heryanto and Rogers, 2002). Despite limited evidence that oestrogen has direct angiogenic effects on endothelial cells (Iruela-Arispe et al., 1999; Razandi et al., 2000), it seems probable that

*Correspondence

Email: peter.rogers@med.monash.edu.au the endometrial angiogenic events described above are regulated at a local level by factors other than oestrogen and progesterone.

It has been hypothesized that numerous different angiogenic factors may be involved during endometrial angiogenesis. Among these are vascular endothelial growth factor (VEGF; Torry and Torry, 1997; Rogers and Gargett, 1999; Smith, 2001), fibroblast growth factor (FGF; Ferriani et al., 1993) and platelet-derived growth factor (PDGF; Smith, 1995; Weston and Rogers, 2000). Previous workers have published evidence for regulation of these angiogenic factors by ovarian steroids. For example, VEGF mRNA expression is upregulated by oestrogen in the endometrium in rats (Cullinan-Bove and Koos, 1993; Hyder et al., 1996), and transfected human endometrial cells in vitro (Mueller et al., 2000). Although the role of progesterone in VEGF production has not been as intensively investigated as that of oestrogen, there are studies indicating that progesterone increases VEGF 
protein expression (Cullinan-Bove and Koos, 1993; Greb et al., 1997; Ancelin et al., 2002).

The presence of FGF in the normal human endometrium and endometriotic tissues has been demonstrated and it has been hypothesized that this growth factor plays a role in the angiogenesis of normal and ectopic endometrium (Ferriani et al., 1993). Oestrogen induces FGF in the primate uterus (Samathanam et al., 1998) and progesterone appears to upregulate FGF expression in the endometrium in rats (Rider and Psychoyos, 1994; Rider et al., 1997). Furthermore, FGF family members play an essential role in the rodent endometrium during pregnancy (Hyder and Stancel, 1999). Taken together, these studies support an assumption that FGF plays an important role in reproductive function including angiogenesis.

Immunohistochemical studies indicate that PDGF is localized in the human endometrium and PDGF receptor- $\beta$ staining intensity is increased during the proliferative phase in luminal and glandular epithelial cells (Chegini et al., 1992). Furthermore, in vitro studies have shown that PDGF promotes endometrial epithelial cell proliferation (Munson et al., 1995) and plays an important role in stromal cell proliferation during endometriosis (Surrey and Halme, 1991). The distribution pattern of PDGF has been described in the mouse endometrium, with luminal and glandular epithelia showing no staining during dioestrus and prooestrus, weak staining during oestrus, and strong staining at days 4 and 5 of gestation (Jaber and Kan, 1998).

Many growth factors mediate their actions through specific cell surface receptors with intrinsic protein tyrosine kinase activity (Ullrich and Schlessinger, 1990). VEGF exerts its cellular functions via two tyrosine kinase receptors, VEGF-1 (fms-like tyrosine kinase 1 (Flt-1)) and VEGF-2 (fetal liver kinase 1 (Flk-1/KDR)) (Ferrara, 1999). Similarly, the biological mechanisms of FGFs are initially mediated by their binding to FGF receptors (Moller et al., 2001) with intrinsic protein tyrosine kinase activity (Mohammadi et al., 1996, 1997). PDGF signals through cell surface tyrosine kinase receptors, PDGFR- $\alpha$ and PDGFR- $\beta$, to induce various cellular activities including proliferation (George, 2001). It has been reported that PDGFR- $\beta$ is upregulated in activated endothelial cells (Plate et al., 1992).

A number of angiogenesis inhibitors have recently become more widely available (Folkman, 2001), including agents that have specificity for different tyrosine kinases. SU5416 blocks signal transduction through the VEGFR-2 receptor, resulting in a reduction in endothelial cell mitogenesis (Strawn et al., 1996; Fong et al., 1999; Geng et al., 2001). SU5402 acts as an inhibitor of FGFR-1 upon co-crystallization with the catalytic domain of FGFR-1 (Mohammadi et al., 1997). The aim of the present study was to determine whether sex steroid-driven endometrial angiogenesis is mediated via VEGF, FGF or PDGF, by using inhibitors to block receptor-mediated activity for each growth factor. Our working hypothesis was that VEGF is the primary angiogenic factor responsible for steroid-driven endometrial angiogenesis.

\section{Materials and Methods}

\section{Animals and hormonal treatments}

Adult female mice (weight 20-25 g, C57 cross CBA strain) were kept under controlled conditions $\left(20^{\circ} \mathrm{C}, 16 \mathrm{~h}\right.$ light: $8 \mathrm{~h}$ dark per day) with food available ad libitum. Induction of mouse endometrial tissue regression and hormonal treatments to induce endometrial endothelial cell proliferation were performed as reported by Heryanto and Rogers (2002). Briefly, mice were ovariectomized bilaterally under anaesthesia (Avertin, $25 \mathrm{mg} 100 \mathrm{~g}^{-1}$ body weight, injected i.p., stock solution: $5 \mathrm{~g} \mathrm{2,2,2-}$ tribromoethanol (Aldrich, Milwaukee, WI) plus $5 \mathrm{ml}$ butan-2-ol (BDH Chemicals, Poole); working solution: $0.25 \mathrm{ml}$ stock solution plus $10 \mathrm{ml} 0.9 \%(\mathrm{w} / \mathrm{v}) \mathrm{NaCl}$ ) to induce endometrial tissue regression. After 7 days, hormonal treatments were given (s.c. in $0.1 \mathrm{ml}$ peanut oil) according to the following regimen: days 1-3: $100 \mathrm{ng}$ oestradiol per day; days 4-6: $10 \mathrm{ng}$ oestradiol and $500 \mu \mathrm{g}$ progesterone per day; and day 7: $100 \mathrm{ng}$ oestradiol and $500 \mu \mathrm{g}$ progesterone. This study was approved by the Monash Medical Centre Animal Ethics Committee A.

\section{SUGEN angiogenesis inhibitor compounds}

In the present study, four pyrrole indolinone angiogenesis inhibitor compounds, SU5416, SU5402, SU11652 and SU11685, were used. SU5416 and SU5402 have been used by many laboratories as inhibitors of Flk-1/KDR and FGFr1 kinases, respectively. Their synthesis has been described by Sun et al. (1998, 1999). The synthetic methods used to prepare SU11652 and SU11685 are in preparation (L. Sun, personal communication). In biochemical assays, SU11652 exhibits nM potencies for inhibition of PDGFR, Flk-1/KDR and FGFR-1 (data not shown). SU11685 exhibits comparable nM potency for inhibition of PDGFR and Flk-1/KDR, but is about tenfold less potent than SU11652 at inhibiting the kinase activity of FGFR-1 (data not shown).

\section{Angiogenesis inhibitor treatments, blood and tissue collection}

The effects of angiogenesis inhibitors SU5416, SU5402, SU11652 and SU11685 on endometrial cell proliferation were investigated on day 1 of oestrogen treatment (E1 stage) and on day 7 after progesterone and high-dose oestrogen treatment (PE stage). For the first time course experiment, groups of six mice were injected s.c. $\left(100 \mathrm{mg} \mathrm{kg}^{-1} \mathrm{day}^{-1}\right)$ with one of the four SUGEN angiogenesis inhibitors (SU5416, SU5402, SU11652 or 
SU11685), or $0.9 \%(\mathrm{w} / \mathrm{v}) \mathrm{NaCl}$ as a control, commencing four days after ovariectomy. The fourth inhibitor injection was combined with oestradiol on day 1 of the hormonal regimen. For the second time course experiment, groups of six mice were injected s.c. $\left(100 \mathrm{mg} \mathrm{kg}^{-1}\right.$ day $\left.^{-1}\right)$ with one of the four inhibitors, or $0.9 \% \mathrm{NaCl}$ as a control, combined with daily hormonal treatment from day 4 of the hormonal regimen to day 7 . The mice were injected i.p. with bromodeoxyuridine (BrdU, 40 mg kg-1 body weight; Sigma, St Louis, MO) $20 \mathrm{~h}$ after the last angiogenesis inhibitor injection for detection of cell proliferation. The mice were anaesthetized $4 \mathrm{~h}$ after BrdU injection and approximately $0.5 \mathrm{~cm}$ of one uterine horn was dissected out and embedded in optimal cutting temperature medium (Sakura Finetek, Torrance, CA) for frozen sections. Blood samples were collected by cardiac puncture from representative animals in each experimental group, and plasma from these samples was stored at $-80^{\circ} \mathrm{C}$ until analysed for concentrations of circulating inhibitors. Mice were perfusion fixed via a cannula inserted in the left ventricle of the heart (perfusion pressure 110-130 mm Hg) using 10\% buffered formalin solution ( $\mathrm{pH} 7.5$ ) after washing out with $0.9 \% \mathrm{NaCl}$. Pilot studies showed that careful perfusion fixation, with a saline washout at physiological pressures, clearly opened the lumen of all identifiable endometrial capillaries. High power microscopic analysis was used to identify endothelial cells lining capillaries that were positive for BrdU. The rest of the uterus was carefully dissected out, immersion fixed with the same fixative then processed for paraffin sections.

\section{VEGF antibody treatment}

A group of six mice was treated with VEGF antiserum raised in rabbit against mouse $\mathrm{VEGF}_{164}$ to investigate further the role of VEGF in endometrial endothelial cell proliferation at the E1 stage (Gargett et al., 1999; Rabbani and Rogers, 2001). Ovariectomized mice were injected i.p. with $0.2 \mathrm{ml}$ rabbit polyclonal anti-VEGF antibody on day 6 after ovariectomy, and a second injection was given with oestradiol on day 1 of the hormonal regimen. The dose was selected on the basis of a pilot study testing $0.2-0.4 \mathrm{ml}$ anti-VEGF antibody. The BrdU treatment, perfusion fixation and tissue collection were performed as described above.

\section{Immunohistochemistry}

Immunohistostaining for cell proliferation detection and capillary profile identification was as described by Heryanto and Rogers (2002). After the tissue sections $(5 \mu \mathrm{m})$ were de-paraffinized and rehydrated, they were microwaved in sodium citrate buffer for antigen retrieval. After cooling to room temperature $\left(20^{\circ} \mathrm{C}\right)$, the sections were treated with $0.1 \mathrm{~mol} \mathrm{HCl} \mathrm{I}{ }^{-1}$ for $45 \mathrm{~min}$. Endogenous peroxidase was blocked by immersing the sections in $3 \% \mathrm{H}_{2} \mathrm{O}_{2}$ in PBS and then the sections were treated with protein blocking solution. The primary antibody, sheep anti-BrdU $\left(10 \mu \mathrm{g} \mathrm{ml}^{-1}\right.$ in $1 \%$ BSA in PBS; BioDesign, Saco, ME) was incubated for $1 \mathrm{~h}$ at room temperature. After washing in PBS, the sections were incubated with biotinylated secondary antibody, donkey anti-sheep (4 $\mathrm{\mu g} \mathrm{ml}^{-1}$ in $1 \%$ BSA in PBS; Jackson Immuno Research Lab Inc., West Grove, PA) for 1 $\mathrm{h}$ at room temperature. The sections were covered with streptavidin-horseradish peroxidase followed by aminoethyl carbazole, a red chromogen, and were counterstained with Mayer's haematoxylin to visualize immunostaining. A positive control section of mouse intestine was included in each staining batch. A negative control slide was prepared by substituting non-immune sheep serum for the primary antibody. The percentage of BrdU-labelled endothelial, stromal and epithelial cells in each endometrial section was calculated. Results were based on counts per section of 300-500 luminal and glandular epithelial cells, 100-200 endothelial cells and 600-800 stromal cells.

The profiles of endometrial capillaries were identified immunohistochemically and counted to evaluate vascular density. The frozen endometrial sections were immersed in $0.3 \% \mathrm{H}_{2} \mathrm{O}_{2}$ in $\mathrm{PBS}$ for $10 \mathrm{~min}$ and treated with $\mathrm{PBA}$ for $10 \mathrm{~min}$ at room temperature after fixing in cold acetone $\left(-20^{\circ} \mathrm{C}\right)$ and air-drying. The endothelial cells were immunostained with a rat monoclonal antibody against mouse CD31 (10 $\mu \mathrm{g} \mathrm{ml}^{-1}$ in $1 \%$ BSA in PBS; PharMingen, Los Angeles, CA) for $1 \mathrm{~h}$ at room temperature. A negative control slide was prepared by substituting purified rat IgG immunoglobulin isotype standard. The sections were incubated with biotinylated secondary antibody and covered with streptavidin-horseradish peroxidase. Immunoreactivity was visualized with aminoethyl carbazole. Vascular density was quantified by counting the number of capillary profiles immunostained for CD31 per $\mathrm{mm}^{2}$. A ratio of vascular density to stromal cell density was calculated for each treatment based on the ratio in each control group equalling one.

\section{Plasma sample preparation and liquid chromatograph and mass spectrometric analysis}

The angiogenesis inhibitor compounds were extracted from the mouse plasma sample after mixing with four parts of the internal standard in acetonitrile (10 ng propanolol $\mathrm{ml}^{-1}$ ). The supernatants were dried after centrifugation $(2750 \mathrm{~g}$ for $10 \mathrm{~min}$ ) under nitrogen at $40^{\circ} \mathrm{C}$ and reconstituted in a 1:1 mixture of mobile phases $A$ and $B$ (see below).

A single calibration curve, over the range 1-2000 ng of each compound per $\mathrm{ml}$, was prepared in the plasma for SU5402, SU11652 and SU11685. A separate calibration curve was prepared for SU5416 over the range 2-200 ng ml ${ }^{-1}$. 
The samples were fractionated on a Shimadzu liquid chromatograph 10AD (Shimadzu Biotech, CA) equipped with a Perkin-Elmer 200 auto-sampler (Perkin-Elmer, CT). For SU5402, SU11652 and SU11685, the samples were fractionated $\left(0.8 \mathrm{ml} \mathrm{min}{ }^{-1}\right)$ on a Keystone Scientific BDS Hypersil C-18 column $(50 \mu \mathrm{m}, 150 \mathrm{~mm} \times 3 \mathrm{~mm}$; Thermo Hypersil-Keystone, PA) at ambient temperature using $90 \%$ water, $10 \%$ acetonitrile and $0.7 \%$ formic acid as mobile phase $\mathrm{A}$, and $10 \%$ water, $90 \%$ acetonitrile and $0.7 \%$ formic acid for mobile phase B. The liquid chromatograph gradient on injection changed from 60:40 A:B to 10:90 over the first $1.5 \mathrm{~min}$. After holding at $10: 90 \mathrm{~A}: \mathrm{B}$ for $0.1 \mathrm{~min}$, the gradient was reversed to 60:40 over $1.9 \mathrm{~min}$, and held for an additional $0.1 \mathrm{~min}$. Tandem mass spectrometric analysis was performed on a Sciex API 365 mass spectrometer (MDS Sciex, Ontario). The limits of quantitation for SU5402, SU11652 and SU11685 were 10, 1 and $2 \mathrm{ng} \mathrm{ml}^{-1}$, respectively.

The samples were fractionated $\left(0.8 \mathrm{ml} \mathrm{min}^{-1}\right)$ for SU5416 on a Keystone Scientific BDS Hypersil C-18 column $(50 \mu \mathrm{m}, 50 \mathrm{~mm} \times 4.6 \mathrm{~mm})$ at ambient temperature using $90 \%$ water, $10 \%$ acetonitrile $10 \mathrm{mmol}$ ammonium acetate $\mathrm{I}^{-1}$ and $0.7 \%$ formic acid as mobile phase $\mathrm{A}$, and $10 \%$ water, $90 \%$ acetonitrile, $10 \mathrm{mmol}$ ammonium acetate $\mathrm{I}^{-1}$ and $0.7 \%$ formic acid for mobile phase B. The mobile phase on injection was held at 70:30 A:B for $1.2 \mathrm{~min}$, and then changed from $70: 30$ $A: B$ to $20: 80$ over 1 min. After holding at 20:80 A:B for $1.5 \mathrm{~min}$, the gradient was reversed to $70: 30$ over $0.1 \mathrm{~min}$, and held for an additional $1.5 \mathrm{~min}$. Tandem mass spectrometric analysis was performed on a Sciex API 3000 mass spectrometer. The limit of quantitation for SU5416 was $2 \mathrm{ng} \mathrm{ml}^{-1}$.

\section{Statistical analyses}

Values are presented as mean \pm SE. The effect of treatment was evaluated by one-way ANOVA followed by Newman-Keuls multiple comparison tests. A $P$ value $<0.05$ was considered significant.

\section{Results}

Effects of angiogenesis inhibitor compounds on endometrial cell proliferation after $24 \mathrm{~h}$ oestrogen stimulation

BrdU immunostaining from stromal areas during the E1 stage is shown (Fig. 1). Proliferating endothelial cells show red nuclear and peri-nuclear immunostaining. Endothelial cell proliferation was increased in the control group (Fig. 1a) and showed the greatest reduction in the group treated with SU5416 (Fig. 1b). Statistical analysis demonstrated that all the angiogenesis inhibitor compounds (SU5416, SU5402, SU11652 and SU11685) significantly reduced the number of BrdU-labelled endothelial cells during the E1 stage (Fig. 2a).
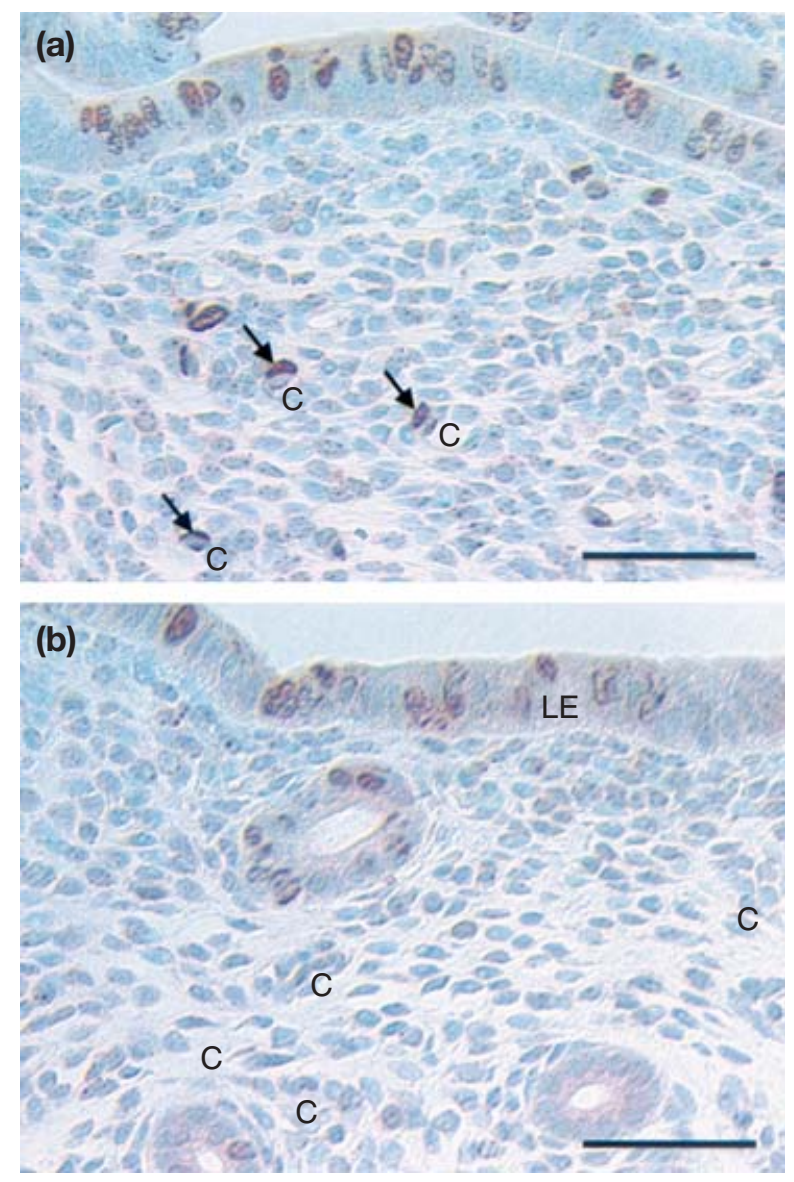

Fig. 1. (a) Section of endometrium immunostained to demonstrate bromodeoxyuridine (BrdU)-labelled cells from a mouse treated with oestrogen. Many endothelial cells are labelled (arrows). (b) Section of endometrium immunostained with anti-BrdU from a mouse treated with oestrogen and SU5416. Endothelial cell labelling is significantly lower than in (a). C: capillary; LE: luminal epithelium. Scale bars represent $50 \mu \mathrm{m}$.

The angiogenesis inhibitor compounds also showed some effect on the luminal epithelial cells. Proliferative activity was significantly decreased in the group treated with SU5402 $(P<0.05)$ and appeared reduced in the group treated with SU5416. There was no significant change in the groups treated with SU11652 or SU11685 (Fig. 2b)

Proliferative activity in glandular epithelial and stromal cells was low and undetectable, respectively. There was no significant difference in the glandular epithelial cell-labelling index between the groups (Fig. 2C).

\section{Effect of angiogenesis inhibitor compounds on vascular} and stromal cell density after 24 h oestrogen stimulation

The effects of angiogenesis inhibitor compounds on vascular and stromal cell density at the E1 stage are summarized (Fig. 3a,b). Although there was no significant difference between these groups, there was a tendency for the number of capillaries and stromal cells per $\mathrm{mm}^{2}$ 
(a)

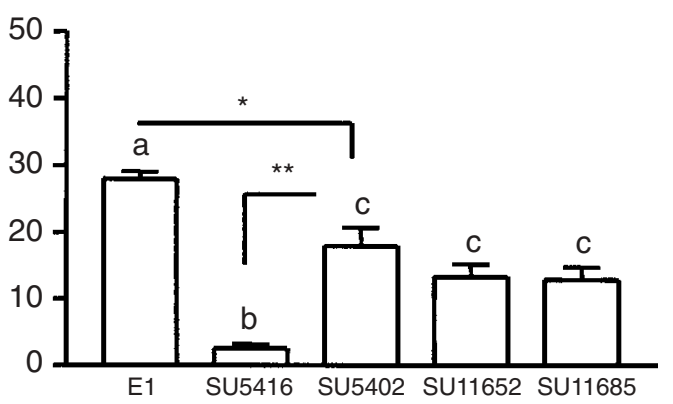

(b)

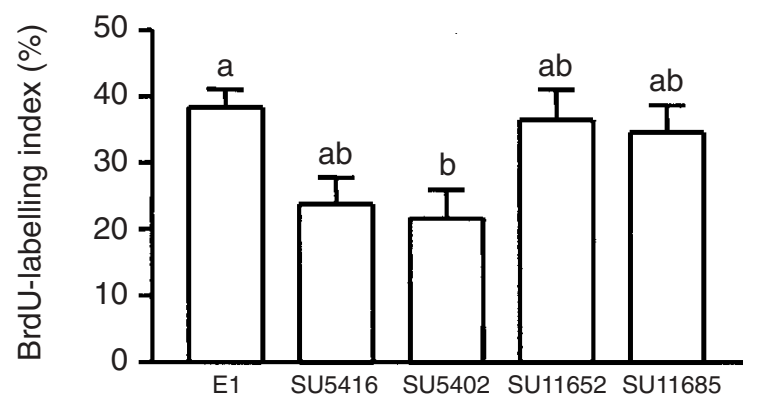

(c)

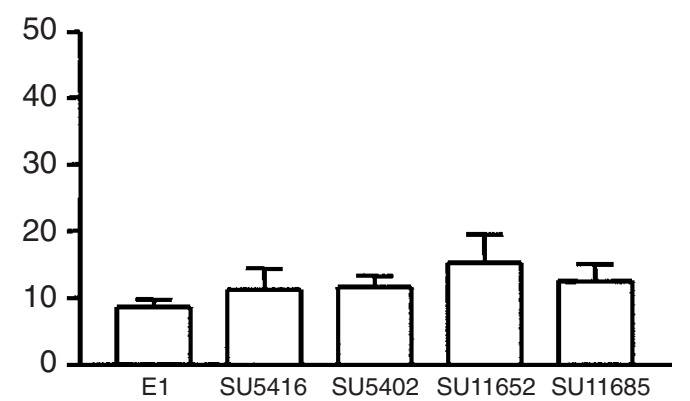

Fig. 2. Endometrial bromodeoxyuridine (BrdU)-labelling indices (\%) for (a) endothelium, (b) luminal epithelium and (c) glandular epithelium in mice treated with the angiogenesis inhibitor compounds SU5416, SU5420, SU11652 and SU11685. Columns with different superscripts are significantly different from each other (a-c $P<0.05$; ${ }^{*} P<0.01$; and $\left.{ }^{* *} P<0.001\right)$; columns with the same superscripts are not significantly different from each other. Values are mean \pm SE ( $n=6$ mice per group). E1: day 1 of oestrogen treatment.

to be slightly higher in the groups treated with SU5416, SU5402 or SU11685 compared with the control group. There was no significant change in the ratio of vascular density to stromal cell density with any treatment (Fig. 3c).

\section{Effect of angiogenesis inhibitor compounds on} endometrial cell proliferation after treatment for 7 days with a combined oestrogen and progesterone protocol

All four of the angiogenesis inhibitor compounds significantly reduced endothelial cell proliferative activity (a)

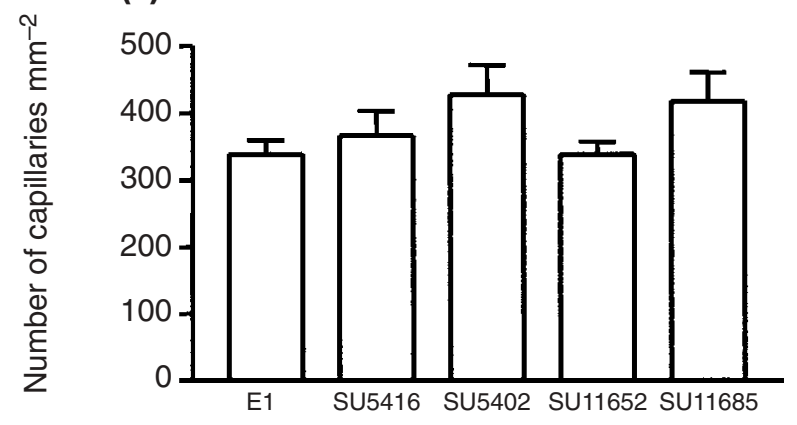

(b)

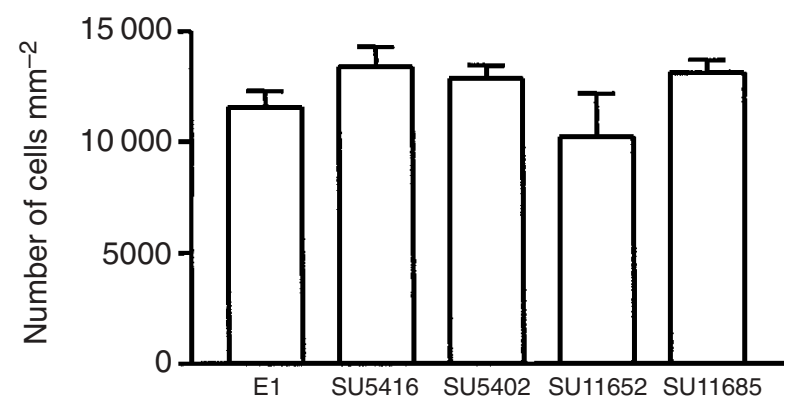

(c)

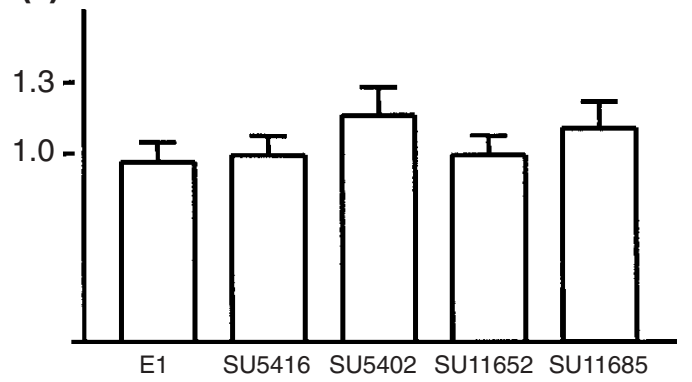

Fig. 3. Quantitative evaluation of endometrial (a) vascular and (b) stromal cell density, and (c) the ratio of vascular density to stromal cell density in mice after treatment with oestrogen and different angiogenesis inhibitors (all values have been proportionally adjusted so that the ratio of vascular to stromal cell density at $\mathrm{E} 1=1)$. Values are mean $\pm \mathrm{SE}(n=6$ mice per group). E1: day 1 of oestrogen treatment. There are no significant differences among the groups.

at the PE stage $(P<0.01)$. In contrast to the result at $\mathrm{E} 1$, there were no differences in the extent of reduction of the BrdU-labelling index between the four treated groups at the PE stage (Fig. 4a).

The angiogenesis inhibitor compounds significantly reduced the proliferative activity in the luminal epithelium in groups treated with SU5416, SU5402, SU11652 $(P<0.01)$ and SU11685 $(P<0.05)$ compared with the control group. There was no significant difference in the BrdU-labelling index of the luminal epithelium among the four treated groups (Fig. 4b).

Proliferative activity in the glandular epithelium was low at the PE stage in all of the groups (data not shown). 
(a)

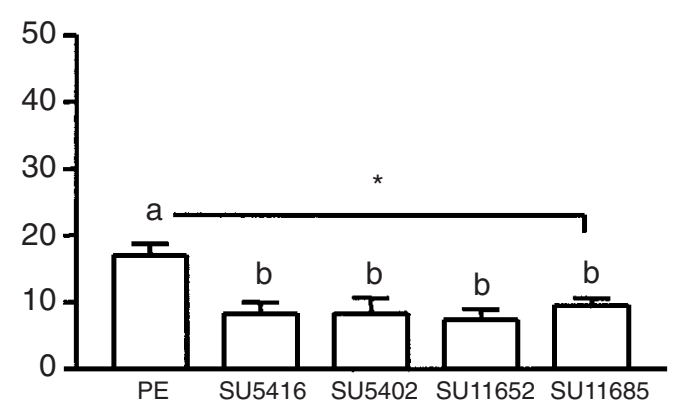

(b)

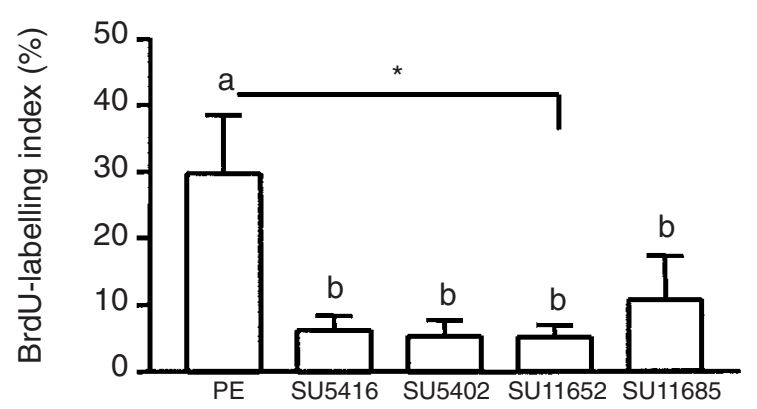

(c)

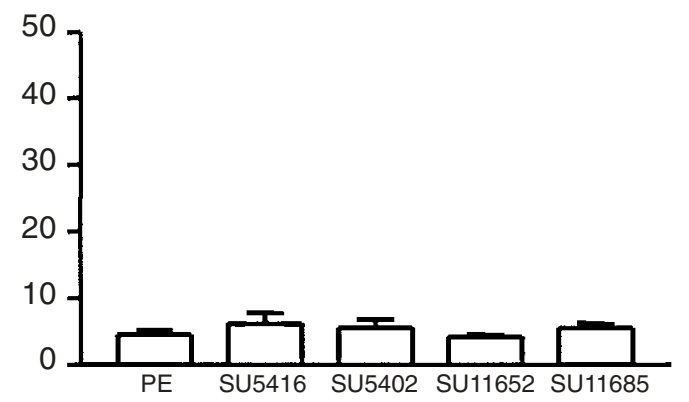

Fig. 4. Endometrial bromodeoxyuridine (BrdU)-labelling indices (\%) in (a) endothelium, (b) luminal epithelium and (c) stromal cells in mice after treatment with progesterone and oestrogen plus different angiogenesis inhibitors. Columns with different superscripts are significantly different from each other ${ }^{\mathrm{a}, \mathrm{b}} P<0.05$ and $* P<0.01$ ); columns with the same superscripts are not significantly different from each other. Values are mean $\pm \operatorname{SE}(n=6$ mice per group). PE: day of progesterone and high-dose oestrogen treatment.

Some proliferative activity occurred in stromal cells at the PE stage; however, there was no significant difference in the BrdU-labelling index among the inhibitor-treated groups (Fig. 4c).

Effect of angiogenesis inhibitor compounds on vascular and stromal cell density after treatment for 7 days with a combined oestrogen and progesterone protocol

There was no significant difference in vascular and stromal cell density between control groups and groups treated at the PE stage. There was a tendency for blood (a)

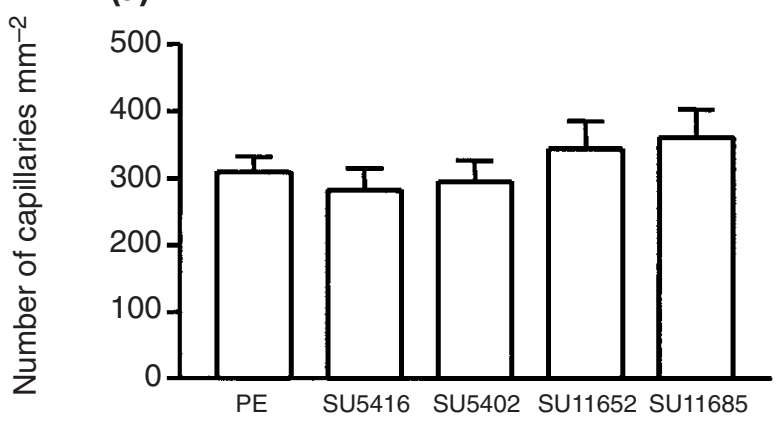

(b)

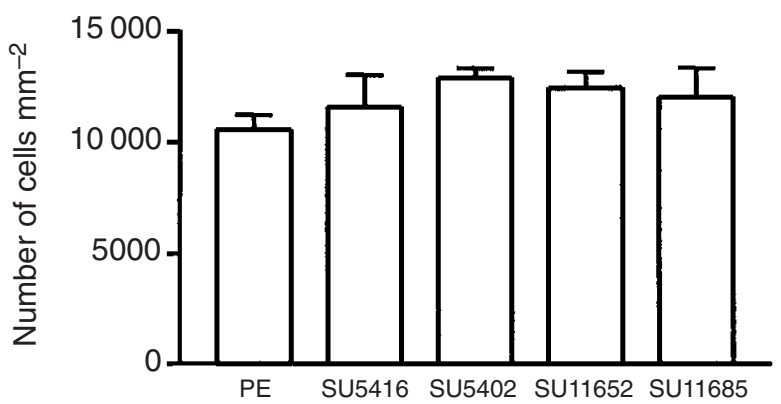

(c)

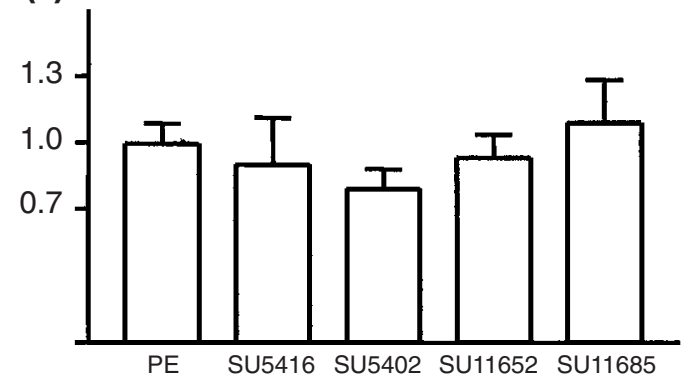

Fig. 5. Quantitative evaluation of endometrial (a) vascular and (b) stromal cell density, and (c) the ratio of vascular density to stromal cell density in mice after treatment with different angiogenesis inhibitors (all values have been proportionally adjusted so that the ratio of vascular to stromal cell density at $\mathrm{PE}=1)$. Values are mean \pm SE ( $n=6$ mice per group). PE: day of progesterone and high-dose oestrogen treatment. There are no significant differences among the groups.

vessel density (BVD) to be slightly increased in groups treated with SU11652 and SU11685 (Fig. 5a). The stromal cell density increased slightly in all the treated groups compared with the control group (Fig. 5b). Apart from the group treated with SU11685, the angiogenesis inhibitor treatments tended to reduce the ratio of BVD to stromal cell density slightly at the PE stage (Fig. 5c).

\section{Effect of VEGF antibody treatment on endothelial cell proliferation and vascular and stromal cell density}

Treatment with VEGF antiserum significantly reduced endothelial cell proliferative activity compared with 


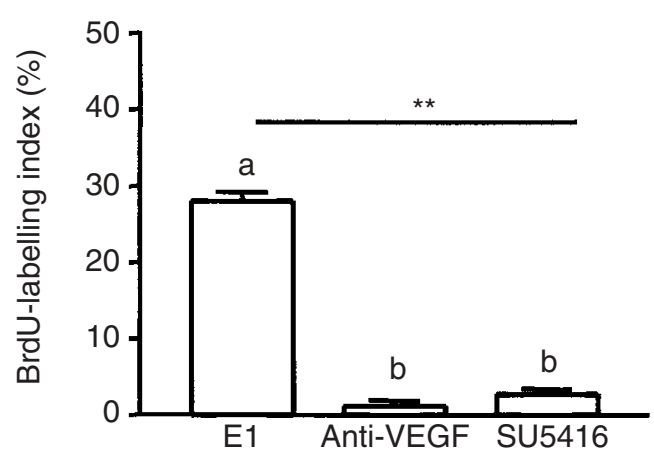

Fig. 6. Endothelial bromodeoxyuridine (BrdU)-labelling indices $(\%)$ in the mouse endometrium at the $\mathrm{E} 1$ stage either untreated or treated with VEGF antibody or SU5416. Columns with different superscripts are significantly different from each other $\left({ }^{* *} P<\right.$ $0.001)$; columns with the same superscripts are not significantly different from each other. Values are mean \pm SE $(n=6$ mice per group). E1: day 1 of oestrogen treatment.

Table 1. Individual concentrations of four SUGEN angiogenesis inhibitor compounds $\left(\mathrm{g} \mathrm{ml}^{-1}\right)$ in a limited number of mouse plasma samples demonstrating typical values achieved

\begin{tabular}{lcccr}
\hline Stage & SU5416 & SU5402 & SU11652 & SU11685 \\
\hline E1 & 23.6 & $<10$ & 94.6 & 821 \\
& 80.4 & $<10$ & 45.9 & 2650 \\
PE & 27.4 & $<10$ & 56.4 & 761 \\
& 39.4 & & & 1380 \\
\hline
\end{tabular}

E1: day 1 of oestrogen treatment; PE: day of progesterone and high-dose oestrogen treatment.

control $(P<0.001)$, resulting in activity similar to that seen in the group treated with SU5416 (Fig. 6). There was no significant effect of VEGF antiserum on BVD compared with control, as was seen with the SU5416 group (Fig. 7a). However, stromal cell density in the group treated with VEGF antiserum was significantly higher than control or the SU5416 group (Fig. 7b). As a consequence, the ratio of BVD to stromal cell density was lower in the group treated with VEGF antiserum than in the control or SU5416-treated group.

\section{Identification of inhibitor compounds in plasma}

Concentrations of each inhibitor compound as assayed in a limited number of plasma samples are presented (Table 1). There was no apparent difference in the concentration of each compound between the E1 and PE stages.

\section{Discussion}

The results from the present study provide the first mechanistic evidence identifying an individual angiogenic factor by which the sex steroid oestrogen drives endometrial angiogenesis. This study has shown

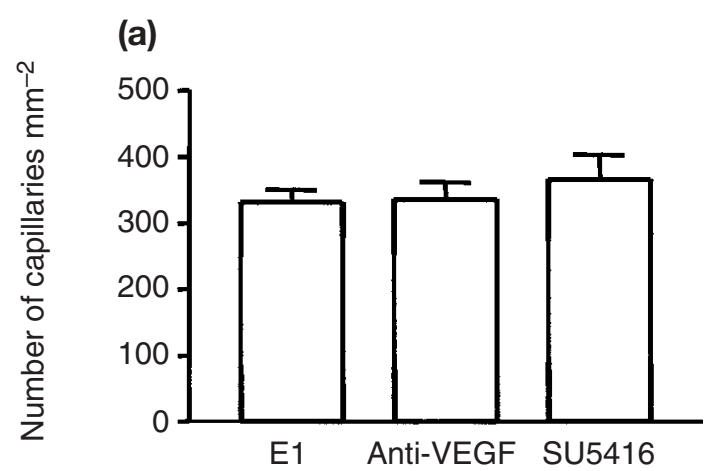

(b)

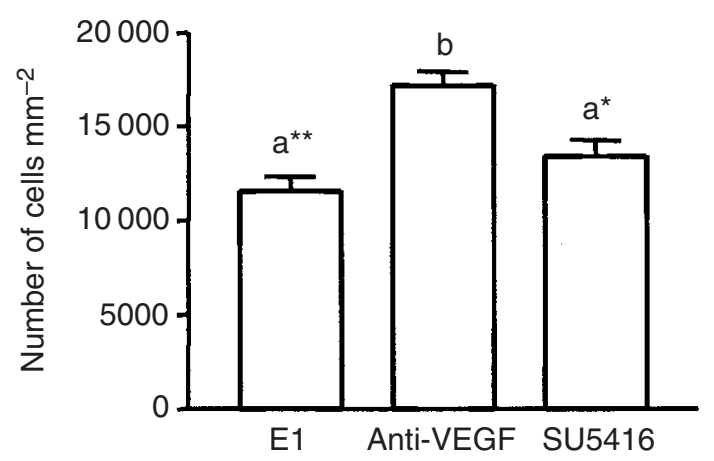

(c)

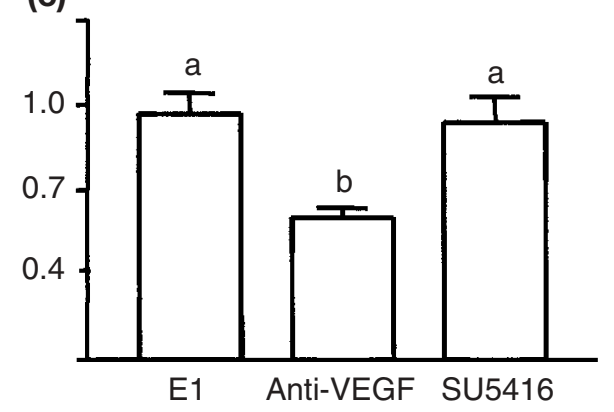

Fig. 7. Quantitative evaluation of (a) vascular and (b) stromal cell density, and (c) the ratio of vascular density to stromal cell density in the mouse endometrium at the E1 stage either untreated or treated with anti-VEGF antibody or SU5416 (all values have been proportionally adjusted so that the ratio of vascular to stromal cell density at $\mathrm{E} 1=1$ ). Columns with different superscripts are significantly different from each other $\left({ }^{\mathrm{a}, \mathrm{b}} P<0.05 ;{ }^{*} P<0.01\right.$ and $\left.{ }^{* *} P<0.001\right)$; columns with the same superscripts are not significantly different from each other. Values are mean $\pm \mathrm{SE}(n=$ 6 mice per group). E1: day 1 of oestrogen treatment.

that SU5416, which inhibits signal transduction through VEGFR-2, and VEGF-antiserum, both almost completely eliminate endometrial endothelial cell proliferation 24 $\mathrm{h}$ after oestrogen treatment. These data demonstrate that the initial angiogenic activity of oestrogen on endometrium is primarily mediated via VEGF. The results of the present study do not provide any information on whether the actions of VEGF in the endometrium occur primarily through VEGFR-2, or whether activation of VEGFR-1 too plays a role. 
There are several possible explanations for the observation that SU11652 and SU11685, which are more potent inhibitors of VEGFR-2 than SU5416 and VEGFantiserum, did not completely inhibit the endothelial cell proliferative activity at the E1 stage. Sub-optimal bioavailability or distribution upon subcutaneous administration is one possible explanation. However, the plasma concentrations of SU11652 and SU11685 are equal to or greater than that of SU5416, indicating that this is not likely to be the sole explanation. Another contributing factor may be the unusual property of SU5416 to accumulate inside the endothelial cells (Mendel et al., 2000). This intracellular accumulation raises the possibility that plasma concentrations of SU5416 underestimate the local concentration of the compound in the cell, thereby conferring additional apparent potency and a longer duration of action to SU5416.

Administration of each of the angiogenic inhibitor compounds over the 4 days before and during the PE stage significantly inhibited endometrial endothelial cell proliferative activity. Inhibition of the endometrial endothelial cell proliferation index at the PE stage was comparable for all four compounds, with none demonstrating the profound inhibition observed with SU5416 at E1. This observation indicates that VEGF is not the only angiogenic factor driving endothelial cell proliferation after exposure to progesterone and oestrogen. It has been reported that several growth factors including VEGF (Rabbani and Rogers, 2001), FGF (Carlone and Rider, 1993) and PDGF (Rodriquez-Martinez et al., 1992) have important roles in endometrial angiogenesis during early pregnancy. It would thus not be unexpected that inhibitors of each of these angiogenic factors decrease endothelial cell proliferation at this stage. However, the apparent poor bioavailability of SU11652 and SU11685 upon subcutaneous administration makes it impossible to determine the contribution these other growth factors may be making, or if there might be additional angiogenic factors contributing to the mitogenic response of endothelial cells at the PE stage. Nevertheless, the clear difference in response to SU5416 between the E1 and PE stages demonstrates that additional factors contribute to the regulation of angiogenesis under these two different sex steroid regimens.

The present data indicate that administration of SU5402 reduces luminal epithelial cell proliferative activity at the E1 stage. It is also possible that SU5416 inhibited luminal epithelial cell proliferation at the E1 stage, although statistical analysis does not show this effect to be significant. The other inhibitor compounds, including anti-VEGF antibody (data not shown), did not have any effect in reducing luminal epithelial cell proliferation at the $\mathrm{E} 1$ stage.

It has been reported that basic FGF (bFGF) is localized in the basal lamina of the glandular and surface epithelial layer of the mouse endometrium (Wordinger et al., 1992). Oestrogen induces luminal epithelial cell proliferation in the ovariectomized mouse at the E1 stage (Heryanto and Rogers, 2002), and other studies have shown that oestrogen rapidly stimulates bFGF mRNA in the endometrial tissue of ovariectomized rats (Rider et al., 1997). These observations may help to explain why blocking FGFR tyrosine kinase activity with SU5402 inhibits luminal epithelial proliferation at this stage.

Each of the angiogenic inhibitor compounds reduced luminal epithelial cell proliferative activity at the PE stage, as was also the case for endometrial endothelial cell proliferative activity. These results indicate that VEGF, FGF and PDGF may play a role in controlling luminal epithelial cell proliferation. Previous workers have reported a role for each of these growth factors during preparation of the luminal epithelium for implantation and placentation. bFGF increases luminal epithelial cell proliferation in early pregnant rats (Rider and Psychoyos, 1994; Srivastava et al., 1998), and PDGF has an important role in luminal cell proliferative activity during early pregnancy in mice (Jaber and Kan, 1998). It has also been reported that VEGF mRNA accumulates in the luminal epithelial cells of the endometrium in mice during days 1 and 2 of pregnancy (Chakraborty et al., 1995; Halder et al., 2000).

The angiogenic inhibitor compounds did not significantly influence vascular and stromal cell density or the ratio of vascular density to stromal cell density at either the E1 or PE stage. Interpretation of this finding is not straightforward because of the different factors that govern endometrial BVD. It is important to remember that endometrial regression results in an increase in BVD, and that sex steroid treatment reduces absolute BVD, at least in part by increasing tissue oedema (Heryanto and Rogers, 2002). However, tissue oedema and increases in stromal cell size significantly reduce stromal cell density after oestrogen treatment, resulting in an increase in BVD when it is measured as a ratio of stromal cell density rather than per unit area. In the present study, there were no significant changes in BVD or stromal cell density at either the E1 or PE stage. This finding indicates that sex steroid effects on stromal cell growth and tissue oedema were basically unaffected by the angiogenesis inhibitors at the doses used. In contrast, the VEGF antiserum significantly increased stromal cell density, indicating that in contrast to the angiogenesis inhibitors, it was reducing endometrial vascular permeability by blocking VEGF action. The lack of any significant changes in absolute BVD throughout the inhibitor experiments indicates that this may not be a sensitive measure of angiogenesis, presumably because of the major influences that growth and regression of the surrounding tissue can have on it.

The present study found no significant effect of angiogenic inhibitor compounds on glandular epithelial or stromal cell proliferative activity. These results indicate that VEGF, FGF and PDGF are not the primary factors promoting glandular epithelial and stromal cell proliferation in the endometrium. 
The results from the current study indicate that several growth factors including VEGF, FGF and PDGF contribute to endometrial endothelial cell proliferation in response to oestrogen and progesterone. Understanding of this complementarity, or redundancy, of growth factors may be more effectively achieved by studies using different combinations of inhibitor compounds.

The present study also demonstrated wide variability in plasma concentration of inhibitors, with the average concentration of SU5402 being less than $10 \mathrm{ng} \mathrm{ml}^{-1}$, whereas the concentration of SU11685 was more than $1000 \mathrm{ng} \mathrm{ml}^{-1}$. It has been shown that a single exposure of SU5416 has a duration of inhibition for proliferation of human umbilical vein endothelial cells of less than $24 \mathrm{~h}$ (Fong et al., 1999). However, it appears that a once-a-day dosing regimen is efficacious for SU5416 because this compound has long-lasting effects (Mendel et al., 2000). Further studies are required to determine whether different dose rates or routes of administration would result in different plasma concentrations and give altered endothelial cell proliferation results.

In conclusion, this study has demonstrated that angiogenesis inhibitor compounds reduce endothelial cell proliferation under two different sex steroid-driven episodes of endometrial angiogenesis. The response of the endometrial endothelial cells was different at each stage, indicating that the factors that regulate angiogenesis under these two different episodes are different.

The authors wish to thank E. Plise, J. Sukbuntherng, F. Lederman and L. Cann for technical advice and assistance. This study was funded in part by NH \& MRC grant number 124331 .

\section{References}

Ancelin M, Buteau-Lozano H, Meduri G, Osborne-Pellegrin M, Sordello S, Plouet J and Perrot-Applanat $\boldsymbol{M}$ (2002) A dynamic shift of VEGF isoforms with a transient and selective progesterone-induced expression of VEGF $_{189}$ regulates angiogenesis and vascular permeability in human uterus Proceedings National Academy of Sciences USA 99 6023-6028

Carlone DL and Rider V (1993) Embryonic modulation of basic fibroblast growth factor in the rat uterus Biology of Reproduction 49 653-665

Chakraborty I, Das SK and Dey SK (1995) Differential expression of vascular endothelial growth factor and its receptor mRNAs in the mouse uterus around the time of implantation Journal of Endocrinology 147 339-352

Chegini N, Rossi MJ and Masterson BJ (1992) Platelet-derived growth factor (PDGF), epidermal growth factor (EGF), and EGF and PDGF betareceptors in human endometrial tissue: localization and in vitro action Endocrinology 130 2373-2385

Cullinan-Bove K and Koos RD (1993) Vascular endothelial growth factor/ vascular permeability factor expression in the rat uterus: rapid stimulation by estrogen correlates with estrogen-induced increases in uterine capillary permeability and growth Endocrinology 133 829-837

Ferrara N (1999) Molecular and biological properties of vascular endothelial growth factor Journal of Molecular Medicine 77 527-543

Ferriani RA, Charnock-Jones DS, Prentice A, Thomas EJ and Smith SK (1993) Immunohistochemical localization of acidic and basic fibroblast growth factors in normal human endometrium and endometriosis and the detection of their mRNA by polymerase chain reaction Human Reproduction 8 11-16

Folkman J (2001) Angiogenesis-dependent diseases Seminars in Oncology $28536-542$
Fong TAT, Shaver LK, Sun L et al. (1999) SU5416 is a potent and selective inhibitor of the vascular endothelial growth factor receptor (Flk-1/KDR) that inhibits tyrosine kinase catalysis, tumor vascularization, and growth of multiple tumor types Cancer Research 39 99-106

Gargett C, Lederman F, Lau TM, Taylor NH and Rogers PAW (1999) Lack of correlation between vascular endothelial growth factor and endothelial cell proliferation in the human endometrium Human Reproduction $\mathbf{1 4}$ 2080-2088

Geng L, Donnelly E, McMahon G, Lin PC, Sierra-Rivera E, Oshinka H and Hallahan DE (2001) Inhibition of vascular endothelial growth factor receptor signalling leads to reversal of tumor resistance to radiotherapy Cancer Research 61 2413-2419

George D (2001) Platelet-derived growth factor receptors: a therapeutic target in solid tumor Seminars in Oncology 5 Supplement 17 2733

Greb RR, Heikinheimo O, Williams RF, Hodgen GD and Goodman AL (1997) Vascular endothelial growth factor in primate endometrium is regulated by receptor-receptor and progesterone-receptor ligands in vivo. Human Reproduction 12 1280-1292

Halder JB, Zhao X, Soker S, Paria BC, Klagsburn M, das SK and Dey SK (2000) Differential expression of VEGF isoforms and VEGF (164)-specific receptor neuropilin-1 in the mouse uterus suggests a role for VEGF (164) in vascular permeability and angiogenesis during implantation Genesis 26 213-224

Heryanto B and Rogers PAW (2002) Regulation of endometrial endothelial cell proliferation by oestrogen and progesterone in the ovariectomised mouse Reproduction 123 107-113

Hyder SM and Stancel GM (1999) Regulation of angiogenic growth factors in the female reproductive tract by estrogen and progestins Molecular Endocrinology 13 806-811

Hyder SM, Stancel GM, Chiappetta C, Murthy L, Boettger-Tong HL and Makela S (1996) Uterine expression on vascular endothelial growth factor is increased by estradiol and tamoxifen Cancer Research $\mathbf{5 6}$ 3954-3960

Iruela-Arispe ML, Rodriquez-Manzaneque JC and Abu-Jawdeh G (1999) Endometrial endothelial cells express estrogen and progesterone receptors and exhibit a tissue specific response to angiogenic factors Microcirculation 6 127-140

Jaber L and Kan FW (1998) Non-identical distribution pattern of epidermal growth factor and platelet-derived growth factor in the mouse uterus during the oestrous cycle and early pregnancy Histochemical Journal 30 $711-722$

Mendel DB, Schreck RE, West DC, Li G, Strawn LM, Tanciongco SS, Vasile S, Shawver LK and Cherrington JM (2000) The angiogenesis inhibitor SU5416 has long-lasting effects on vascular endothelial growth factor receptor phosphorylation and function Clinical Cancer Research 6 4848-4858

Mohammadi M, Schlessinger J and Hubbard SR (1996) Structure of the FGF receptor tyrosine kinase domain reveals a novel autoinhibitory mechanism Cell 86 577-587

Mohammadi M, McMahon G, Sun L, Tang C, Hirth P, Yeh BK, Hubbard SR and Schlessinger J (1997) Structures of the tyrosine kinase domain of fibroblast growth factor receptor in complex with inhibitors Science 276 955-960

Moller B, Rasmussen C, Lindblom B and Olovsson M (2001) Expression of the angiogenic growth factors VEGF, FGF-2, and EGF and their receptors in normal human endometrium during menstrual cycle Molecular Human Reproduction 7 65-72

Mueller MD, Vigne JL, Minchenko A, Lebovic DI, Leitman DC and Taylor RN (2000) Regulation of vascular endothelial growth factor (VEGF) gene transcription by estrogen receptor $\alpha$ and $\beta$ Proceedings National Academy of Sciences USA 97 10 972-10977

Munson L, Upadhyaya NB and Van Meter S (1995) Platelet-derived growth factor promotes endometrial epithelial cell proliferation American Journal of Obstetrics and Gynaecology 173 1820-1825

Plate KH, Breier G, Farrell CL and Risau W (1992) Platelet-derived growth factor receptor-b is induced during tumor development and upregulated during tumor progression in endothelial cells in human gliomas Laboratory Investigation 67 529-534 
Rabbani M and Rogers PAW (2001) Role of vascular endothelial growth factor in endometrial vascular events before implantation in rats Reproduction 122 85-90

Razandi M, Pedram A and Levin ER (2000) Estrogen signals to the preservation of endothelial cell form and function Journal of Biological Chemistry 27538 540-38546

Rider V and Psychoyos A (1994) Inhibition of progesterone receptor function results in loss of basic fibroblast growth factor expression and stromal cell proliferation during uterine remodelling in the pregnant rat Journal of Endocrinology 140 239-249

Rider V, Carlone DL and Foster RT (1997) Oestrogen and progesterone control basic fibroblast growth factor mRNA in the rat uterus Journal of Endocrinology 154 75-85

Rodriguez-Martinez H, Persson E, Hurst $\mathbf{M}$ and Stanchev $\mathbf{P}$ (1992) Immunohistochemical localization of platelet-derived growth factor receptors in the porcine uterus during the oestrous cycle and pregnancy Zentralblatt fur Veterinarmedizin. Reihe A 39 1-10

Rogers PAW and Gargett CE (1999) Endometrial angiogenesis Angiogenesis 2 287-294

Samathanam CA, Adesanya OO, Zhou J, Wang J and Bondy CA (1998) Fibroblast growth factors 1 and 2 in the primate uterus Biology of Reproduction 59 491-496

Smith SK (1995) Angiogenic growth factor expression in the uterus Human Reproduction Update 1 162-172

Smith SK (2001) Regulation of angiogenesis in the endometrium Trends in Endocrinology and Metabolism 12 147-151

Srivastava RK, Gu Y, Ayloo S, Zilberstein M and Gibori G (1998) Developmental expression and regulation of basic fibroblast growth factor and vascular endothelial growth factor in rat decidua and in decidual cell line Journal of Molecular Endocrinology 21 355-362

Strawn LM, MacMahon G, App H et al. (1996) Flk-1 as a target for tumor growth inhibition Cancer Research 56 3540-3545
Sun L, Tran N, Tang F, App H, Hirth P, McMahon G and Tang C (1998) Synthesis and biological evaluation of 3-substituted indolin-2-ones: a novel class of tyrosine kinase inhibitors that exhibit selectivity toward particular receptor tyrosine kinases Journal of Medicinal Chemistry 41 2588-2603

Sun L, Tran N, Liang C, Tang F, Rice A, Schreck R, Waltz K, Shawver LK, McMahon G and Tang C (1999) Design, synthesis, and evaluation of substituted 3-[(3- or 4-carboxyethylpyrrol-2-yl)methylidenyl]indolin-2ones as inhibitors of VEGF, FGF, and PDGF receptor tyrosine kinases Journal of Medicinal Chemistry 42 5120-5130

Surrey ES and Halme J (1991) Effect of platelet-derived growth factor on endometrial stromal cell proliferation in vitro: a model for endometriosis Fertility and Sterility 56 672-679

Torry DS and Torry RJ (1997) Angiogenesis and expression of vascular endothelial growth factor in endometrium and placenta American Journal of Reproduction and Immunology 37 21-29

Ullrich A and Schlessinger J (1990) Signal transduction by receptors with tyrosine kinase activity Cell $61203-212$

Weston G and Rogers PAW (2000) Endometrial angiogenesis Bailliere's Best Practice and Research. Clinical Obstetrics and Gynaecology 14919 936

Wordinger RJ, Moss AE, Lockard T, Gray D, Chang IF and Jackson TL (1992) Immunohistochemical localization of basic fibroblast growth factor within the mouse uterus Journal of Reproduction and Fertility 96 141-152

Received 12 August 2002.

First decision 11 October 2002

Revised manuscript received 4 December 2002.

Accepted 13 December 2002. 